\title{
Diketopiperazine from marine bacterium Pseudoalteromonas ruthenica KLPp3
}

\author{
Faiq Sulieman, ${ }^{1}$ Asmat Ahmad, ${ }^{1}$ Gires Usup, ${ }^{2}$ Lu Chung Kuang ${ }^{3}$ \\ ${ }^{1}$ School of Bioscience and Biotechnology, University Kebangsaan Malaysia, Selangor, Malaysia; ${ }^{2}$ School of \\ Environmental Science and Natural Resources, University Kebangsaan Malaysia, Selangor, Malaysia; ${ }^{3}$ National \\ Research Institute of Chinese Medicine, Taipei, Taiwan
}

\begin{abstract}
Sub-minimum inhibitory concentration levels of Pseudoalteromonas ruthenica KLPp3 extract showed antibiofilm activity against Vibrio alginolyticus and Serratia marcescens. The KLPp3 crude extract was fractionated by thin layer chromatography, flash chromatography, solid phase extraction and semi-preparative high performance liquid chromatography. The
\end{abstract}

\footnotetext{
Correspondence: Asmat Ahmad, School of Bioscience and Biotechnology, University Kebangsaan Malaysia, 43600 UKM Bangi, Selangor, Malaysia.

Tel.: +603.89213221 - Fax: +603.89252698

E-mail: asmat@ukm.edu.my
}

Key words: Diketopiperazine; Sub-minimum inhibitory concentrations; Crude extract; Antibiofilm; Pseudoalteromonas ruthenica.

Contributions: FS is the student who has undertaken all the research work; AA is the lecturer who provided designs and approved the protocols to be followed in the study and the intellectual input about isolation and characterization of bacteria; $\mathrm{GU}$ is the lecturer who provided the intellectual input about marine environment and extraction of natural products from bacteria; LCK is the lecturer who provided the high performance liquid chromatography and nuclear magnetic resonance machines and the intellectual input about compounds identification.

Conflict of interest: FS reports grants from MOSTI, during the conduct of the study.

Funding: MOSTI Science Fund (0401-02-SF0754).

Conference presentation: this work was presented at the UKM FST Postgraduate Colloquium and Symposium of Malaysian Society of Applied Biology (MSAB) 2014.

Received for publication: 17 November 2017.

Revision received: 27 April 2018.

Accepted for publication: 29 April 2018

CCopyright F. Sulieman et al., 2018

Licensee PAGEPress, Italy

Journal of Biological Research 2018; $91: 7197$

doi:10.4081/jbr.2018.7197

This article is distributed under the terms of the Creative Commons Attribution Noncommercial License (by-nc 4.0) which permits any noncommercial use, distribution, and reproduction in any medium, provided the original author(s) and source are credited. pure compounds were then identified using H-nuclear magnetic resonance, $\mathrm{C}$-nuclear magnetic resonance, $2 \mathrm{D}$-nuclear magnetic Resonance and mass spectrometry. Nine fractions were collected from purification with two active fractions. One fractions were identified belong to the family of diketopiperazine.

\section{Introduction}

Diketopiperazine are the smallest cyclic peptides known and they are biosynthesized from amino acids by a large variety of organisms including Gram-negative and Gram-positive bacteria, fungi and higher marine organisms. ${ }^{1-4} 90 \%$ of Gram-negative bacteria produce diketopiperazine, ${ }^{5}$ making it one of the sources for diketopiperazine isolation. Since the first report in 1924, a large number of bioactive diketopiperazine was discovered spanning activities as antitumor, antifungal, antibacterial, antiviral, antihyperglycemic and antiprion. ${ }^{5}$

Biofilms in general are considered as surface-associated microorganism communities enclosed in an extracellular polymeric substances. ${ }^{6}$ Marine environment has an optimum condition for formation of biofilm. Bacterial biofilms, frequently in association with diatoms, algae, protozoa and fungi, are found on all submerged man-made structures as well as natural surfaces in the marine environment. Marine bacteria as primary colonizers are known to be responsible for the initiation of biofouling and may cause various damages in maritime activities and industries. ${ }^{7}$ Thus, the need of novel bioactive compounds, which enhance or inhibit the settlement of organisms, is increasing. Marine bacteria are a possible source of such compounds. Indeed, previous studies have demonstrated that a high proportion of microbes isolated from the surfaces of macro-organisms produce diverse bioactive compounds.

Pseudoalteromonas ruthenica KLPp3 (GenBank accession no: KT071710) is a surface-associated bacterium recently isolated by our group from the surface of the marine crab, Scylla serrate. ${ }^{8}$ The aim of this study was to evaluate the effect of $P$. ruthenica extract on the biofilm production of Vibrio alginolyticus and Serratia marscescens at sub-minimum inhibitory concentration (MIC) levels and to identify the pure active compounds.

\section{Materials and Methods}

\section{Bacteria isolation and identification}

Marine bacterium P. ruthenica KLPp3 (GenBank accession no: KT071710) was isolated from surface of a marine crab in Pulau 
Perhentian of Malaysia. The surface of a marine crab from was swabbed using sterile Dacron swabs. The swabs were placed into a $15 \mathrm{~mL}$ sterile plastic tube and the swabs stem were snapped approximately 1 inch from the top of the tube. The isolation of bacteria was done by using serial dilution method. Dilutions were prepared using sterile water with $3 \%$ sodium chloride, and $0.1-\mathrm{mL}$ aliquots were surface spread on Marine agar (MA) (Oxoid). After incubation at $30^{\circ} \mathrm{C}$ for $24 \mathrm{~h}$, the bacterial cultures were transferred to fresh MA for a second incubation.

KLPp3 isolate was identified from the $16 \mathrm{~S}$ ribosomal DNA sequence determination. DNA was extracted using the DNeasy tissue kit (QIAGEN GmbH, Hilden, Germany). PCR amplification using universal primers forward (5' AGA GTT TGA TCC TGG CTC AG 3') and reverse (5' GGT TAC CTT GTT ACG ACT 3') amplified approximately $1,500 \mathrm{bp}$ of the $16 \mathrm{~S}$ ribosomal DNA. Sequencing of the amplified DNA was performed by First Base Laboratories Sdn Bhd.

\section{Test microorganisms}

The biofilm-forming bacteria Serratia marcescens SM-11, $V$. alginolyticus PPjt4, and $V$. alginolyticus $\mathrm{PPbp} 4$ were maintained on nutrient agar (NA; Difco, USA) slants with $3 \%$ sodium chloride at $4^{\circ} \mathrm{C}$ and discarded monthly. Primary stock cultures are stored in glycerol stock at $-80^{\circ} \mathrm{C}$.

\section{Extraction of Pseudoalteromonas ruthenica KLPp3 crude extract}

P. ruthenica KLPp3 was grown in total of $10 \mathrm{~L} \mathrm{LB}$ broth by shaking for 90 hours and was extracted using ethyl acetate. After the incubation, the bacterial culture was centrifuged at $4000 \mathrm{rpm}$ for 15 minutes and the supernatant was filtered through a $0.22 \mu \mathrm{m}$ membrane. The supernatants were extracted with the equal volumes of ethyl acetate. The extraction process was repeated three times and then the extract was concentrated in a rotary evaporator. The crude extracts were stored at $4^{\circ} \mathrm{C}$ and must be analyzed within 2 days. For long-term storage, the crude extracts are maintained at $-80^{\circ} \mathrm{C}$.

\section{Minimum inhibitory concentration}

All bacterial strains were subjected to the antimicrobial tests by using the disc diffusion method on the Mueller-Hinton agar. An aliquot of $0.1 \mathrm{~mL}$ of $0.5 \mathrm{McF}$ arland equivalents, approximately from an exponentially growing culture was spread on the agar for the development of a bacterium strain lawn at $30^{\circ} \mathrm{C}$. Next, on the lawnagar of each plate, eight discs of crude extracts with concentration of $0.1 \mathrm{mg} / \mathrm{mL}, 0.2 \mathrm{mg} / \mathrm{mL}, 0.5 \mathrm{mg} / \mathrm{mL}$ and $1 \mathrm{mg} / \mathrm{mL}$ were placed individually at equal distances from one another. The plates were incubated for 18 hours at $30^{\circ} \mathrm{C}$ and were examined for sizemeasurements of inhibition zones around each disc.

\section{Antibiofilm activity assay}

The biofilm formation of $V$. alginolyticus PPjt4, V. alginolyticus PPbp4 and $S$. marcescens SM-11 was evaluated in the presence of the crude extract and purified compounds. The quantification of the in vitro biofilm production was based on the method previously reported. ${ }^{9}$ Briefly, the wells of a sterile 96-well flat-bottomed polystyrene plate were filled with $100 \mathrm{uL}$ of the appropriate medium. A 1/100 dilution of overnight bacterial culture was added into each well. The first row contained the untreated bacteria, while the second row contained $0.1 \mathrm{mg} / \mathrm{mL}$ of the crude extract. The plates were incubated for $24 \mathrm{~h}$ at $30^{\circ} \mathrm{C}$. After rinsing with $0.9 \%$ saline, the adhered cells were stained with $0.1 \%$ crystal violet, rinsed twice with $0.9 \%$ saline and thoroughly dried. The dye bound to the adherent cells was resolubilized with $80 \%(\mathrm{v} / \mathrm{v})$ ethanol per well. The OD of each well was measured at $590 \mathrm{~nm}$.

\section{Fractionation and compound isolation}

The crude extract was fractionated on a solid phase extraction (SPE) column (C18). Water and Methanol $(\mathrm{MeOH})$ were used as solvent with ratio 3:7, 5:5, 9:1 and 10:0. High performance liquid chromatography (HPLC) purification was accomplished by reverse phase RP18 column (Waters, $5 \mu \mathrm{m}, 4.6 \times 250 \mathrm{~mm}, 5 \mu \mathrm{m}$ particle size). The elution was at a flow rate of $1 \mathrm{~mL} \mathrm{~min}^{-1}$ with two solutions: methanol and distilled water, starting with $5 \% \mathrm{MeOH}$ for $10 \mathrm{~min}$, which was increased linearly to $20 \% \mathrm{AcN}$ in $20 \mathrm{~min}$ and held for 5 min at this level. Then $\mathrm{MeOH}$ was increased linearly to $100 \%$ and held for $5 \mathrm{~min}$ at this level before returning to $5 \% \mathrm{MeOH}$ in $5 \mathrm{~min}$, and then equilibrated for $15 \mathrm{~min}$. HPLC analyses were performed using photodiode array detector with a wavelength range 200$800 \mathrm{~nm}$.

\section{Spectroscopic analysis}

The nuclear magnetic resonance (NMR) spectra were measured on a Varian Mercury Plus $400 \mathrm{FT}-\mathrm{NMR}$ at $400 \mathrm{MHz}$ for ${ }^{1} \mathrm{H}$ and ${ }^{13} \mathrm{C}$, in $\mathrm{CDCl}_{3}$, respectively. As for 2D NMR (COSY, HMBC, HSQC), the spectra were measured at $600 \mathrm{MHz}$ in $\mathrm{CDCl}_{3}$. Silica gel (Merck, 230-400 mesh) and polygoprep gel were used for column chromatography. Mass spectrometry was recorded with Quattro Ultima triple quadrupole mass spectrometer (Waters, Manchester, UK) equipped with an electrospray interface.

\section{Results}

\section{Bacteria identification}

The partial 16S rDNA sequence from the isolate was used for searching in Basic Local Alignment Search Tool and showed 96\% homology to the corresponding sequence of $P$. ruthenica (reference no: AB617563.1)

\section{Minimum inhibitory concentration}

Preliminary experiments were carried out to assess the effects of crude extract on the growth of $V$. alginolyticus PPbp4, $V$. alginolyticus PPjt4 and $S$. marcescens SM-11 (Table 1). The

Table 1. Minimum inhibitory concentration of crude extracts.

\begin{tabular}{|c|c|c|c|c|c|c|}
\hline Tested bacteria & $\begin{array}{c}\text { Inhibition (mm) } \\
0.1 \mathrm{mg} / \mathrm{mL}\end{array}$ & $0.2 \mathrm{mg} / \mathrm{mL}$ & $0.5 \mathrm{mg} / \mathrm{mL}$ & $1 \mathrm{ml} / \mathrm{mL}$ & Negative Control & Positive control \\
\hline S. marcescens & 6 & 6 & 7 & 7 & 6 & 13 (streptomycin) \\
\hline V. algynolyticus $\mathrm{PPbp} 4$ & 6 & 6 & 7 & 7 & 6 & 11 (streptomycin) \\
\hline V. algynolyticus PPjt4 & 6 & 6 & 7 & 7 & 6 & 11(streptomycin) \\
\hline
\end{tabular}


bacterial cultures were separately treated with the crude extract at a concentration of $0.1 \mathrm{mg} / \mathrm{mL}, 0.2 \mathrm{mg} / \mathrm{mL}, 0.5 \mathrm{mg} / \mathrm{mL}$ and $1 \mathrm{mg} / \mathrm{mL}$. The inhibitory effect started at the concentration of $0.5 \mathrm{mg} / \mathrm{mL}$. The MIC of the crude extract was $0.5 \mathrm{mg} / \mathrm{mL}$. There were no inhibitory effects at the concentration of $0.1 \mathrm{mg} / \mathrm{mL}$ and $0.2 \mathrm{mg} / \mathrm{mL}$. This result has shown that the concentration of $0.1 \mathrm{mg} / \mathrm{mL}$ and 0.2 $\mathrm{mg} / \mathrm{mL}$ did not prevent the growth of bacteria. The sub-MIC, 0.1 $\mathrm{mg} / \mathrm{mL}$, was chosen for further tests.

\section{Effects of Pseudoalteromonas ruthenica KLPp3 crude extract on the biofilm formation}

The effects of sub-MIC crude extract of P. ruthenica KLPp3 on biofilm-forming bacteria were examined. It inhibited $59.71 \%$, $45.02 \%$ and $56.4 \%$ of the biofilm production in $V$. alginolyticus $\mathrm{PPbp} 4, V$. alginolyticus $\mathrm{PPjt} 4$ and $S$. marcescens SM-11 respectively (Figure 1A).

\section{Effects of Pseudoalteromonas ruthenica KLPp3 crude extract on the initial attachment}

Initial attachment of the bacteria to a solid surface is the first step in biofilm formation. As reported in Figure 1B, P. ruthenica KLPp3 crude extract reduced the attachment of $V$. alginolyticus PPbp4, V. alginolyticus PPjt4 and S. marcescens SM-11.

\section{Purification and characterization of antibiofilm com- pounds}

Antibiofilm activity of $P$. ruthenica KLPp3 crude extract resulting from growth of $P$. ruthenica KLPp3 in LB broth was recovered in the $90 \%$ methanol phase after SPE on a C18 column. After further separation by HPLC using a RP18 column (Figure 2), each fraction was tested for antibiofilm activity and only two fractions have antibiofilm activity (Figure 3). One compound, KLPP3-4.3a.9 was identified using NMR.

The pure compound KLPP3-4.3a.9 was colourless and dissolved in methanol. The 1HNMR spectrum showed a broad $1 \mathrm{H}$ singlet of an amide at $\delta 5.66 \mathrm{ppm}(4 \mathrm{NH}), 1 \mathrm{H}$ triplet at $\delta 4.56 \mathrm{ppm}$ (H8), five doublet of doublets at $\delta 4.44(\mathrm{H} 6), \delta 4.30(\mathrm{H} 3), \delta 3.76$ (H9), $\delta 3.60$ (H10) and $\delta 2.76$ (H10) ppm, two multiplet at $\delta 2.02$ $(\mathrm{H} 7)$ and $\delta 2.33(\mathrm{H} 7)$, and three doublet at $\delta 3.55$. In addition, aromatic protons consist of two multiplet, two doublet of doublets and a triplet between $\delta$ 7.20-7.35 (H12, H13, H14, H15, H16) ppm. KLPP3-4.3a.9 had the molecular formula $\mathrm{C}_{14} \mathrm{H}_{16} \mathrm{~N}_{2} \mathrm{O}_{3}$, as determined by ESMS $261\left[\mathrm{M}^{+}+\mathrm{H}^{+}\right]$. All of NMR spectrums are shown on Figures 4 and 5. Data from the experiments elucidating the chemical structures of compound KLPP3-4.3a.9 is summarized and compared with two reference compound cyclo(L-Phe-trans-4$\mathrm{OH}-\mathrm{L}-\mathrm{Pro})^{10}$ and cyclo(L- phenylalanyl-4-hydroxy-L-prolin) ${ }^{11}$ in
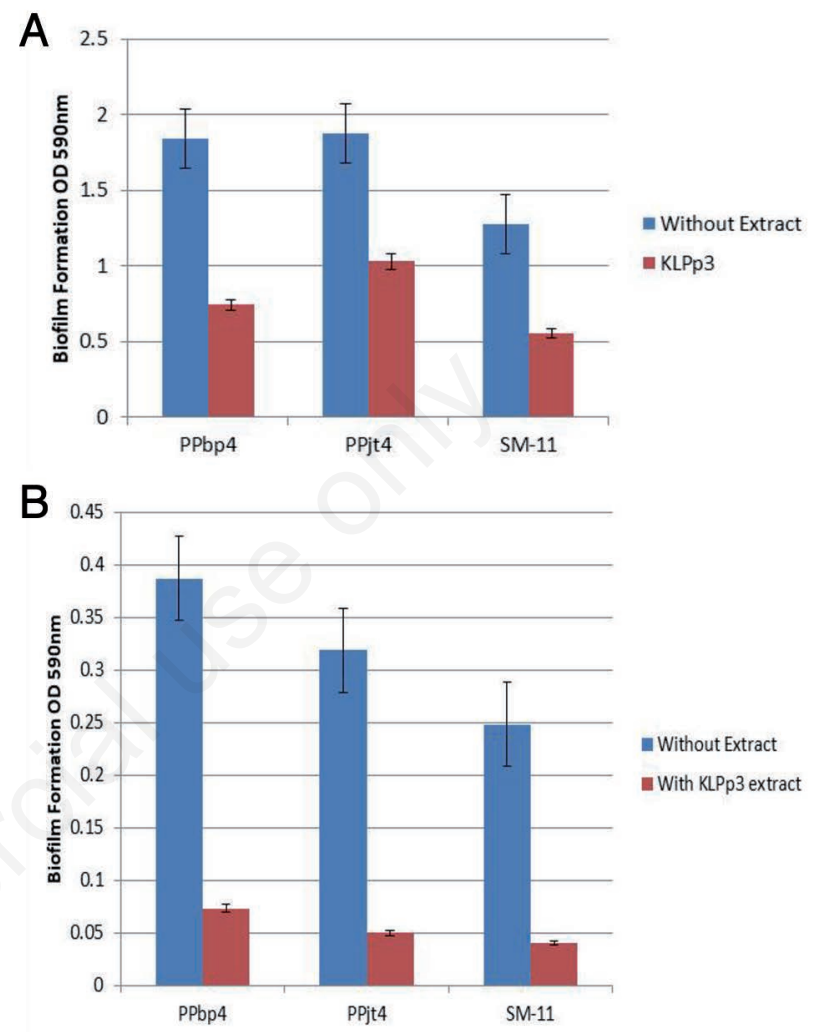

Figure 1. A) Effect of Pseudoalteromonas ruthenica KLPp3 crude extract on biofilm formation; B) Effect of $P$. ruthenica KLPp3 crude extract on initial attachment.

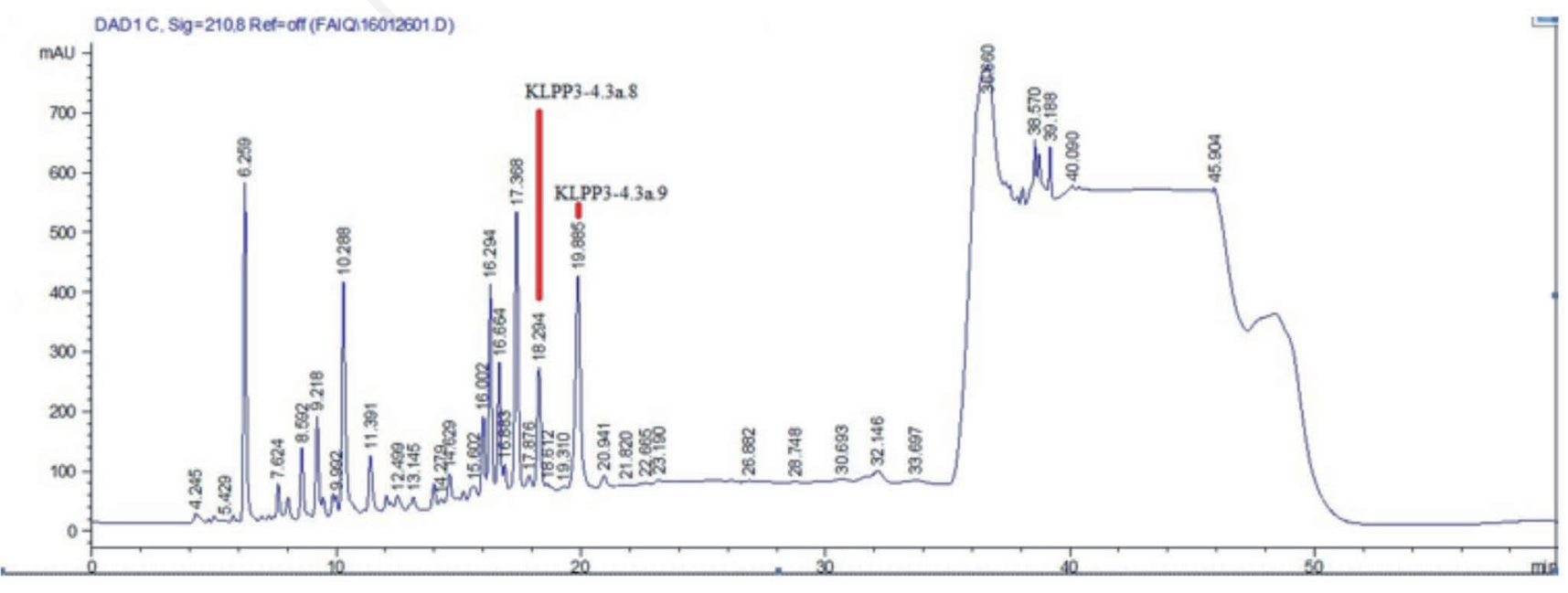

Figure 2. Fractionation of Pseudoalteromonas ruthenica KLPp3 crude extract using high performance liquid chromatography. 
Table 2. KLPP3-4.3a.9 is identified as 3-benzyl-7hydroxyhexahydropyrrolo[1.2a]pyrazine-1,4-dione (Figure 6).

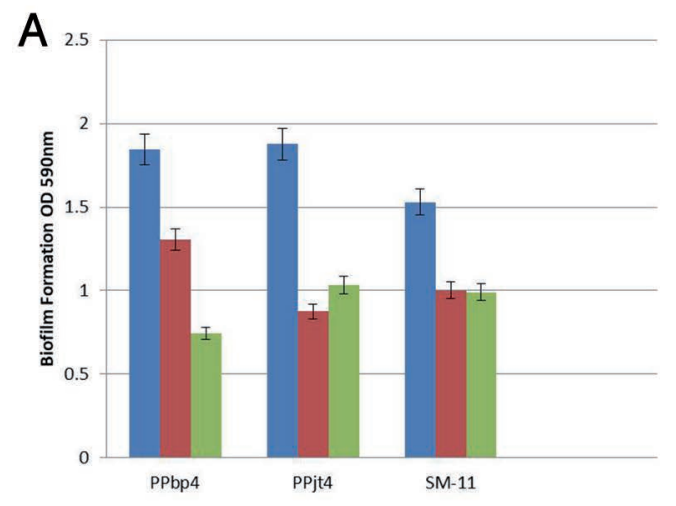

- Without extract = KLPP3-4.3a.8 KLPP3-4.3a.9

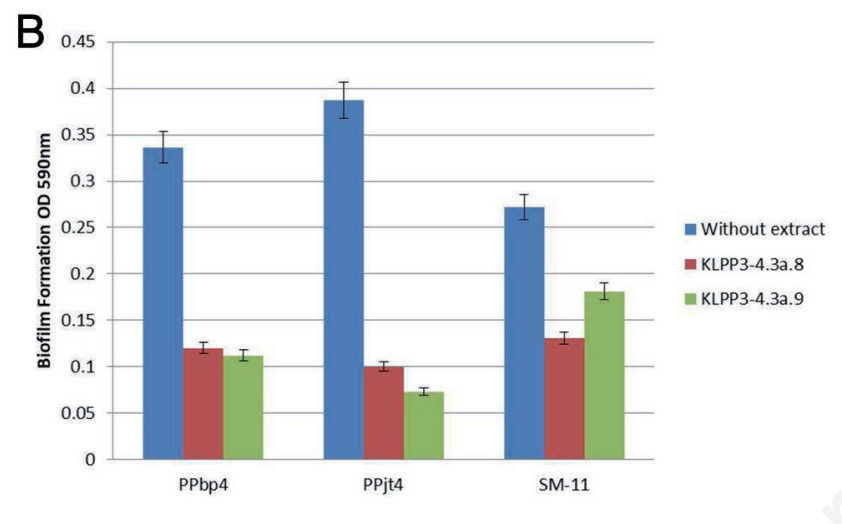

Figure 3. A) Effect of KLPP3-4.3a.8 and KLPP3-4.3a.9 on biofilm formation; B) Effect of KLPP3-4.3a.8 and KLPP3-4.3a.9 on initial attachment.

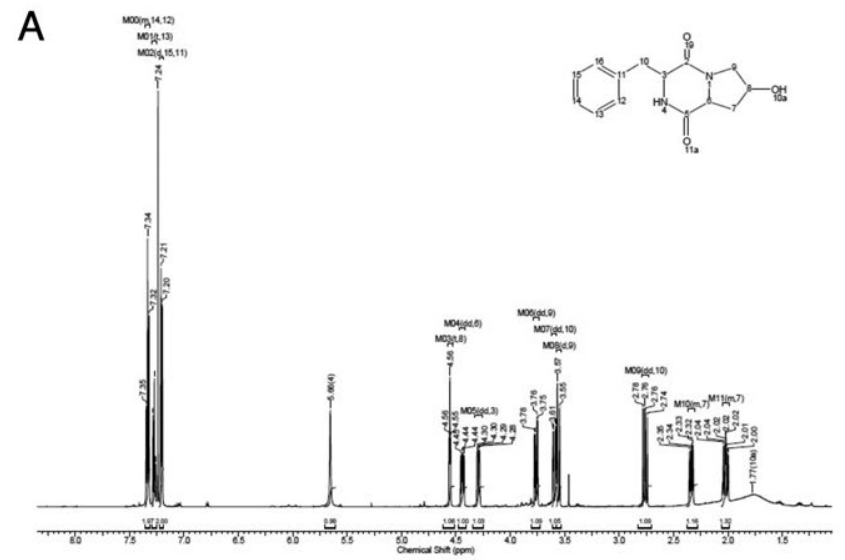

B

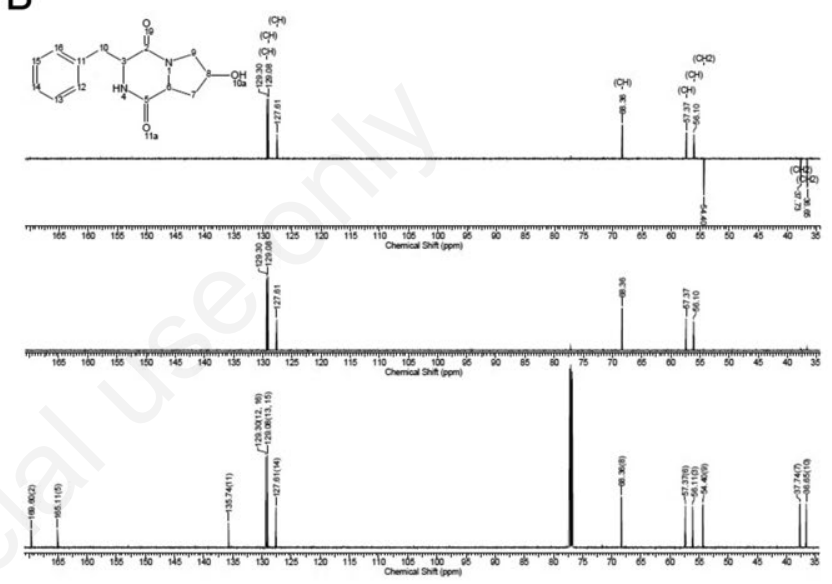

Figure 4. A) H- nuclear magnetic resonance of KLPp3-4.3a.9. B) C- nuclear magnetic resonance of KLPp3-4.3a.9.

Table 2. ${ }^{1} \mathrm{H}$ and ${ }^{13} \mathrm{C}$ nuclear magnetic resonance data for KLPP3-4.3a.9 and its nearest reference compounds.

\begin{tabular}{|c|c|c|c|c|c|c|}
\hline \multirow[t]{2}{*}{ Functional Group } & \multicolumn{2}{|c|}{$\begin{array}{l}\text { Chemical Shift (ppm) } \\
\text { KLPP3-4.3.9 }\end{array}$} & \multicolumn{2}{|c|}{ Ström et al. 10} & \multicolumn{2}{|c|}{ Jiang et $a l .11$} \\
\hline & ${ }^{13} \mathrm{C}$ & ${ }^{1} \mathrm{H}$ & ${ }^{13} \mathrm{C}$ & ${ }^{1} \mathrm{H}$ & ${ }^{13} \mathrm{C}$ & ${ }^{1} \mathrm{H}$ \\
\hline $\mathrm{C}=\mathrm{O}$ & 169.60 & - & 171.29 & & 169.4 & \\
\hline $\mathrm{C}-\mathrm{H}$ & 56.11 & 4.30 & 57.65 & 4.48 & 56.0 & 4.30 \\
\hline $\mathrm{N}-\mathrm{H}$ & - & 5.66 & - & 7.95 & & 5.65 \\
\hline $\mathrm{C}=\mathrm{O}$ & 165.11 & - & 167.19 & & 165.0 & \\
\hline $\mathrm{C}-\mathrm{H}$ & 57.37 & 4.44 & 55.19 & 4.37 & 57.3 & 4.45 \\
\hline $\mathrm{C}-\mathrm{H} 2$ & 37.74 & $\begin{array}{l}2.33 \\
2.02\end{array}$ & 38.76 & $\begin{array}{l}2.07 \\
1.39\end{array}$ & 37.6 & $\begin{array}{l}2.35 \\
2.08\end{array}$ \\
\hline $\mathrm{C}-\mathrm{H}$ & 68.36 & 4.56 & 68.65 & 4.28 & 68.3 & 4.58 \\
\hline $\mathrm{C}-\mathrm{H}_{2}$ & 54.40 & $\begin{array}{l}3.76 \\
3.55\end{array}$ & 58.35 & $\begin{array}{l}3.71 \\
3.29 \\
\end{array}$ & 54.3 & $\begin{array}{l}3.78 \\
3.57 \\
\end{array}$ \\
\hline $\mathrm{C}-\mathrm{H}_{2}-\mathrm{Ph}$ & 36.65 & $\begin{array}{l}3.60 \\
2.76\end{array}$ & 37.95 & 3.17 & 36.5 & $\begin{array}{l}3.64 \\
2.76\end{array}$ \\
\hline $\mathrm{C}$ & 135.74 & - & 137.51 & & 135.6 & \\
\hline $\mathrm{CH}$ & 129.30 & $7.20-7.21$ & 131.14 & 7.24 & 129.2 & 7.25 \\
\hline $\mathrm{CH}$ & 129.08 & 7.32-7.35 & 129.63 & 7.27 & 129.2 & 7.25 \\
\hline $\mathrm{CH}$ & 127.61 & 7.27 & 128.23 & 7.22 & 129.0 & 7.25 \\
\hline $\mathrm{CH}$ & 129.08 & $7.32-7.35$ & 129.63 & 7.27 & 127.5 & 7.25 \\
\hline $\mathrm{CH}$ & 129.30 & $7.20-7.21$ & 131.14 & 7.24 & 129.0 & 7.25 \\
\hline
\end{tabular}



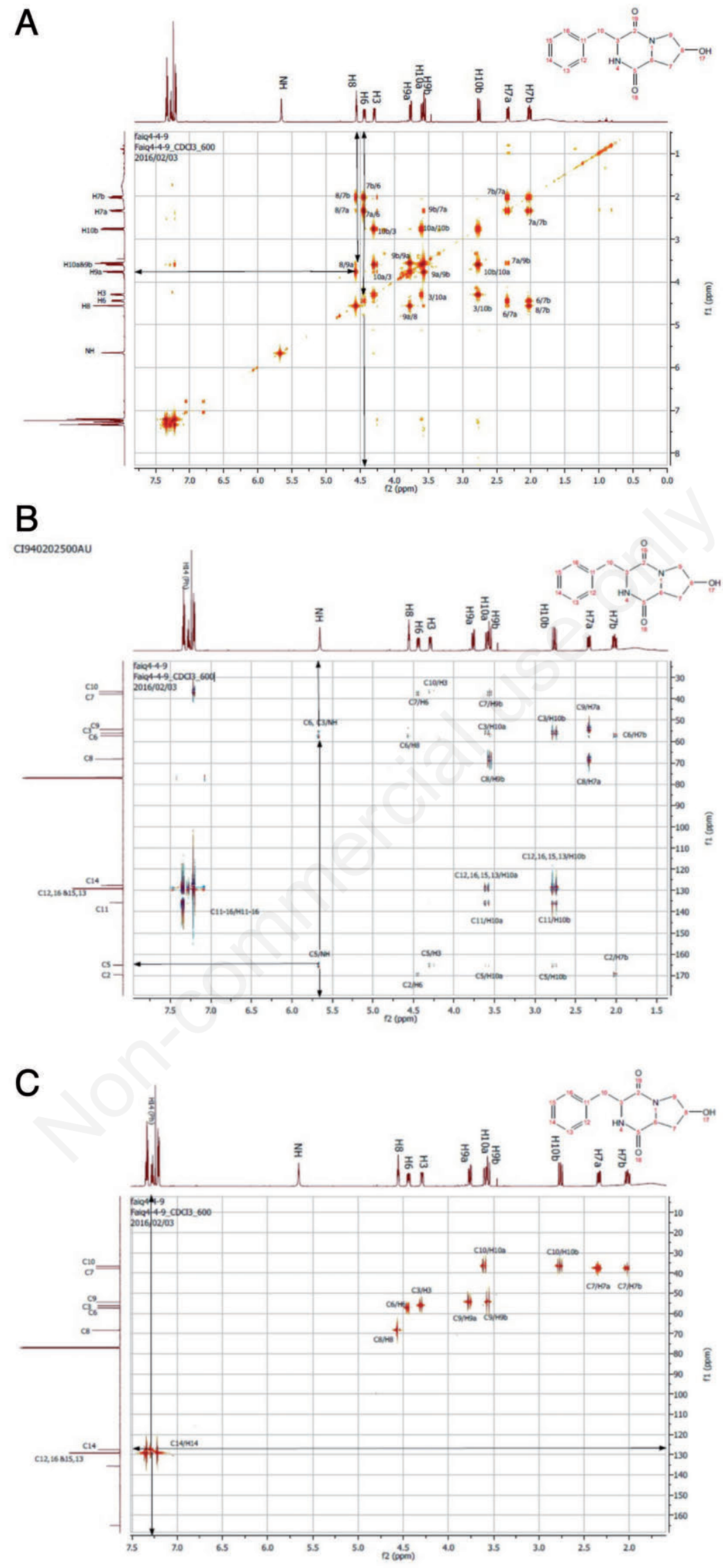

Figure 5. A) COSY nuclear magnetic resonance of KLPp3-4.3a.9; B) HMBC nuclear magnetic resonance of KLPp3-4.3a.9; C) HSQC nuclear magnetic resonance of KLPp3-4.3a.9. 


\section{Discussion}

Sub-MIC of antibiotic allows susceptible strains to continue growing. Studies show that the sub-MICs of antibiotic can reduce the ability of the biofilm production without killing the targets. ${ }^{12,13}$ Sub-MIC level of $P$. ruthenica KLPp3 crude extract could have potential as antibiofilm, reducing initial attachment and biofilm formation. When tested against matured biofilm, it did not show any effect (data is not shown). These may indicate that $P$. ruthenica KLPp3 crude extract inhibit biofilm formation by disturbing initial attachment. Previously reported that sub-MIC of antibiotics was able to inhibit the attachment of Pseudomonas aeruginosa. ${ }^{14}$ It has been reported that the adherence of Streptococcus mutans and Streptococcus sobrinus to saliva-coated hydroxyapatite (sHA) discs were reduced by extract of Withania somnifera at sub-MIC concentrations. ${ }^{15}$ Studies show that the sub-MICs of antibiotics and antimicrobial compounds can reduce the ability of the biofilm production without killing the targets. ${ }^{14,16}$

The crude extract targeted $V$. alginolyticus, one of the pioneers of biofilm formation. Huang et al. suggest that vibrios in the seawater tend to attach to a surface and are one of the pioneer groups in the biofilm community. ${ }^{17}$ The molecular confirmation of dominant genera in marine biofilm subjected to $16 \mathrm{~s}$ rDNA results reveals initial marine biofilm forming bacteria was $V$. alginolyticus. ${ }^{18}$ It had been reported that $V$. alginolyticus employed biofilm formation to survive in the marine environments and cause vibriosis in shrimp and biofouling in the process. ${ }^{18,19}$

One antibiofilm substances was identified. The presence of cyclic dipeptide that consists of a six-membered ring containing two amide linkages where the two nitrogen atoms and the two carbonyls are at opposite positions in the ring both suggest that the compound is diketopiperazine. The chemical structures was determined as 3benzyl-7-hydroxyhexahydropyrrolo[1.2a]pyrazine-1,4-dione. Cyclo(L-Phe-trans-4-OH-L-Pro) has previously been reported to be both antibacterial and antifungal but never before been used as antibiofilm activity. 5,20

\section{Conclusions}

In conclusion, 3-benzyl-7-hydroxyhexahydropyrrolo[1.2a] pyrazine-1,4-dione produced by $P$. ruthenica KLPp3 inhibits in vitro biofilm formation. The inhibitory effect of 3-benzyl-7hydroxyhexahydropyrrolo[1.2a]pyrazine-1,4-dione maybe due to inhibition of pre-formed biofilms by blocking the attachment of bacteria to surfaces.

\section{References}

1. Sammes P. Naturally occurring 2,5-dioxopiperazines and related compounds. Fortschr Chem Org Naturst 1975;32:51-118.

2. Rosa D, Mito M, Tommonaro G. Marine bacteria associated with sponge as source of cyclic peptides. Biomol Eng 2003;20:311-6.

3. Bugni TS, Ireland CM. Marine-derived fungi: a chemically and biologically diverse group of microorganisms. Nat Prod Rep 2004;21:143-63.

4. Huang R, Zhou X, Xu T, et al. Diketopiperazines from marine organisms. Chem Biodivers 2010;7:2809-29.

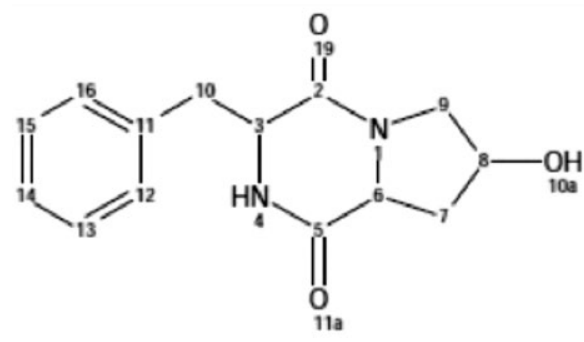

Figure 6. Chemical structure of KLPp3-4.3a.9.

5. De Carvalho MP, Abraham W. Antimicrobial and biofilm inhibiting diketopiperazines. Curr Med Chem 2012;19:3564-77.

6. Hall-Stoodley L, Costerton JW, Stoodley P. Bacterial biofilms: from the natural environment to infectious diseases. Nat Rev Microbiol 2004;2:95-108.

7. Doghri I, Rodrigues S, Bazire A, et al. Marine bacteria from the French Atlantic coast displaying high forming-biofilm abilities and different biofilm 3D architectures. BMC Microbiol 2015;15:231.

8. Ahmad A, Faiq M, Sulieman I, Usup G. Anti-biofilm activity of the marine bacterium Pseudoalteromonas ruthenica KLPp3 against Serratia marcescens and Vibrio alginolyticus. Malays J Microbiol 2016;12:30-4.

9. Papa R, Parrilli E, Sannino F, et al. Anti-biofilm activity of the Antarctic marine bacterium Pseudoalteromonas haloplanktis TAC125. Res Microbiol 2013;164:450-6.

10. Ström K, Sjögren J, Broberg A, Schnürer J. Lactobacillus plantarum MiLAB 393 produces the antifungal cyclic dipeptides cyclo (L -Phe - L -Pro) and cyclo (L -Phe-trans-4OH-L-Pro) and 3-Phenyllactic Acid. Appl Environ Microbiol 2002;6:4322-7.

11. Jiang Z, Boyd KG, Mearns-spragg A, et al. Two diketopiperazines and one halogenated phenol from cultures of the marine bacterium, Pseudoalteromonas luteoviolacea. Nat Prod Lett 2000;14:435-40.

12. Henriques M, Cerca N, Azeredo J, Oliveira R. Influence of subinhibitory concentrations of antimicrobial agents on biofilm formation in indwelling medical devices. Int $\mathrm{J}$ Artif Organs 2005;28:1181-5.

13. Wojnicz D, Tichaczek-Goska D. Effect of sub-minimum inhibitory concentrations of ciprofloxacin, amikacin and colistin on biofilm formation and virulence factors of Escherichia coli planktonic and biofilm forms isolated from human urine. Brazil J Microbiol 2013;44:259-65.

14. Dosler S, Karaaslan E. Inhibition and destruction of Pseudomonas aeruginosa biofilms by antibiotics and antimicrobial peptides. Peptides 2014;62:32-7.

15. Pandit S, Chang KW, Jeon JG. Effects of Withania somnifera on the growth and virulence properties of Streptococcus mutans and Streptococcus sobrinus at sub-MIC levels. Anaerobe 2013;19:1-8.

16. Packiavathy IASV, Priya S, Pandian SK, Ravi AV. Inhibition of biofilm development of uropathogens by curcumin - An antiquorum sensing agent from Curcuma longa. Food Chem 2014;148:453-60.

17. Huang Y, Ki J, Lee OO, Qian P. Evidence for the dynamics of Acyl homoserine lactone and AHL-producing bacteria during subtidal biofilm formation. ISME J 2009;296-304. 
Litopenaeus vannamei and its resistance against Vibrio alginolyticus. J Fish Soc Taiwan 2013;40:241-56.

20. Fdhila F, Vázquez V, Sánchez JL, Riguera R. DDDiketopiperazines: Antibiotics active against Vibrio anguillarum isolated from marine bacteria associated with cultures of Pecten maximus. J Nat Prod 2003;66:1299-301. 